OPEN ACCESS

Edited by:

Biswarup Mukhopadhyay, Virginia Polytechnic Institute and State

University, USA

Reviewed by:

Yves André Muller,

University Erlangen-Nuremberg,

Germany

Sylvie Nessler,

University Paris-Sud, France

Jacqueline Plumbridge,

Centre National de la Recherche

Scientifique, France

${ }^{*}$ Correspondence:

Graciela L. Lorca

glorca@ufl.edu

Specialty section:

This article was submitted to Microbial Physiology and Metabolism,

a section of the journa

Frontiers in Microbiology

Received: 21 October 2015

Accepted: 19 January 2016

Published: 09 February 2016

Citation:

Blancato VS, Pagliai FA, Magni C, Gonzalez CF and Lorca GL (2016)

Functional Analysis of the Citrate

Activator CitO from Enterococcus faecalis Implicates a Divalent Metal in

Ligand Binding.

Front. Microbiol. 7:101.

doi: 10.3389/fmicb.2016.00101

\section{Functional Analysis of the Citrate Activator CitO from Enterococcus faecalis Implicates a Divalent Metal in Ligand Binding}

\author{
Víctor S. Blancato ${ }^{1,2}$, Fernando A. Pagliai ${ }^{2}$, Christian Magni ${ }^{1}$, Claudio F. Gonzalez ${ }^{2}$ and \\ Graciela L. Lorca ${ }^{2 *}$ \\ ${ }^{1}$ Laboratorio de Fisiología y Genética de Bacterias Lácticas, Instituto de Biología Molecular de Rosario, Consejo Nacional de \\ Investigaciones Científicas y Técnicas, Rosario, Argentina, ${ }^{2}$ Department of Microbiology and Cell Science, Genetics Institute, \\ Institute of Food and Agricultural Science, University of Florida, Gainesville, FL, USA
}

The regulator of citrate metabolism, CitO, from Enterococcus faecalis belongs to the FCD family within the GntR superfamily. In the presence of citrate, CitO binds to cis-acting sequences located upstream of the cit promoters inducing the expression of genes involved in citrate utilization. The quantification of the molecular binding affinities, performed by isothermal titration calorimetry (ITC), indicated that CitO has a high affinity for citrate $\left(K_{D}=1.2 \pm 0.2 \mu \mathrm{M}\right)$, while it did not recognize other metabolic intermediates. Based on a structural model of CitO where a putative small molecule and a metal binding site were identified, it was hypothesized that the metal ion is required for citrate binding. In agreement with this model, citrate binding to CitO sharply decreased when the protein was incubated with EDTA. This effect was reverted by the addition of $\mathrm{Ni}^{2+}$, and $\mathrm{Zn}^{2+}$ to a lesser extent. Structure-based site-directed mutagenesis was conducted and it was found that changes to alanine in residues Arg97 and His191 resulted in decreased binding affinities for citrate, as determined by EMSA and ITC. Further assays using lacZ fusions confirmed that these residues in CitO are involved in sensing citrate in vivo. These results indicate that the molecular modifications induced by a ligand and a metal binding in the C-terminal domain of CitO are required for optimal DNA binding activity, and consequently, transcriptional activation.

Keywords: Enterococcus, metalloprotein, citrate, FadR family, FCD domain

\section{INTRODUCTION}

Members of the GntR superfamily of transcription factors, Pfam PF00392 (Bateman et al., 2002), are found in diverse bacterial genomes. This group of proteins was first described in 1991 and named after the gluconate operon repressor in Bacillus subtilis (Haydon and Guest, 1991). GntRlike regulators are known to control many fundamental cellular processes, such as motility (Jaques and Mccarter, 2006), development (Hoskisson et al., 2006), antibiotic production (Ostash et al., 2011), antibiotic resistance (Truong-Bolduc and Hooper, 2007), plasmid transfer (Reuther et al., 2006), and virulence (Casali et al., 2006). However, most of the specific small molecules that act as a signal to regulate the expression of the respective genes are unknown. 
The canonical scaffold of the GntR superfamily consist of a DNA-binding winged helix-turn-helix topology (HTH motif, followed by a $\beta$-hairpin) in the $\mathrm{N}$-terminus of the protein. The effector-binding domain, which also functions as the oligomerization domain, is usually located at the C-terminus of the protein. Upon binding of an effector molecule at the Cterminal domain, a conformational change occurs in the protein affecting the DNA-binding properties of the regulator. These conformational changes will result in repression or activation of gene transcription (Van Aalten et al., 2001). The C-terminal regulatory ligand binding domain differs significantly among individual proteins and is currently used to classify members of this superfamily into six major families: HutC, MocR, YtrA, AraR, PlmA, and FCD (FadR C-terminal Domain; Rigali et al., 2002; Lee et al., 2003; Franco et al., 2006; Zheng et al., 2009). Although the tertiary structures of several members of these large families are well described and publically available, the information on their sensory ligands and ligand binding pockets is very scarce. The FCD family clusters more than $40 \%$ of all GntR members, with FadR from E. coli, the regulator for fatty acid biosynthesis and degradation, being one of the best characterized (Van Aalten et al., 2000, 2001).

CitO, a member of the FCD Family, is the transcription factor required for the expression of the genes involved in citrate metabolism in Enterococcus faecalis. The cit cluster is encoded in two divergent operons: citHO encoding for the citrate transporter $\mathrm{citH}$, and the regulatory protein citO. The catabolic enzymes are encoded upstream, in the minus strand, in the oadHDB-citCDEFX-oadA-citMG operon (Blancato et al., 2006, 2008; Espariz et al., 2011; Repizo et al., 2013). There are two binding elements for $\mathrm{CitO}$ in the intergenic region, which regulate the expression of genes involved in the transport and degradation of citrate. In presence of citrate, $\mathrm{CitO}$ binds to the cis-acting sequences located in the cit intergenic region. In the citHO operon coding strand, $\mathrm{CitO}$ protects the region between positions -41 and -65 (binding site $\mathrm{O}_{1}$ ); whereas in the oadHDB-citCDEFX-oadA-citMG operon, CitO protects the region between positions -51 and -74 (binding site $\mathrm{O}_{2}$; Figure 1A). We previously showed that the interaction with citrate increased the binding of CitO to the DNA, and that the $\mathrm{CitO} /$ citrate complex had higher affinity for the $\mathrm{O}_{1}$ than the $\mathrm{O}_{2}$ binding site. Interestingly, in vivo and in vitro experiments suggest that $\mathrm{CitO}$ is specifically activated only by citrate and not by other metabolic intermediates, such as malate, succinate, or even by its isomer, isocitrate (Blancato et al., 2008). However, the molecular mechanisms of such specificity were not investigated.

In the present study, we report the analysis of the binding affinities of E. faecalis CitO for citrate. The binding pocket in $\mathrm{CitO}$ was analyzed by site-directed mutagenesis and the critical amino acids involved in the ligand binding were identified. Furthermore, we found that binding of a divalent cations, $\mathrm{Ni}^{2+}$, or $\mathrm{Zn}^{2+}$ in the C-terminus of the protein improved CitO-citrate interactions.

\footnotetext{
Abbreviations: EMSA, Electrophoretic mobility shift assays; DSF, Differential scanning fluorimetry; ITC, Isothermal Titration Calorimetry; Tm, melting temperature; IPC-AES, inductively coupled plasma atomic emission spectrometry.
}

\section{MATERIALS AND METHODS}

\section{Bacterial Strains and Growth Conditions}

The bacterial strains and plasmids used in this study are listed in Table 1. E. coli strains were grown at $37^{\circ} \mathrm{C}$ under aerobic conditions in Luria-Bertani medium (LB) (Difco), or on LB agar plates. E. coli $\mathrm{DH} 5 \alpha$ (Invitrogen, Carlslab, CA) was used to propagate the plasmids for protein purification and sitedirected mutagenesis. E. coli strain BL21(DE3)-Star (Novagen, Gibbstown, NJ) was used to express CitO. When required, the medium was supplemented with ampicillin $(100 \mu \mathrm{g} / \mathrm{ml})$ or kanamycin $(50 \mu \mathrm{g} / \mathrm{ml})$. All antibiotics and chemicals were purchased from Sigma-Aldrich (St. Louis, MO).

E. faecalis strains were routinely grown at $37^{\circ} \mathrm{C}$ without shaking in $100 \mathrm{ml}$ sealed bottles filled with $20-50 \mathrm{ml}$ of $\mathrm{LB}$ medium containing $0.5 \% \mathrm{w} / \mathrm{v}$ glucose. Erythromycin $(5 \mu \mathrm{g} / \mathrm{ml})$, kanamycin $(1000 \mu \mathrm{g} / \mathrm{ml})$, or chloramphenicol $(10 \mu \mathrm{g} / \mathrm{ml})$ were added when appropriate.

\section{DNA Manipulations and Gene Cloning}

Standard methods were used for chromosomal DNA isolation, restriction enzyme digestion, agarose gel electrophoresis, ligation, and transformation (Sambrook and Russell, 2001). Plasmids were isolated using spin miniprep kits (Qiagen, Valencia, CA) and PCR products were purified using QIAquick purification kits (Qiagen). All the primers used for this study are described in Table 2. The plasmids for protein purification, protein expression in E. faecalis, and transcriptional fusions are previously described in Blancato et al. (2008).

Site-directed mutagenesis was performed using the QuikChange Site-directed Mutagenesis kit (Stratagene) according to the manufacturer's protocol. Plasmids pETcitO or pCitO were used as the templates. All the selected amino acids were changed to alanine. The mutations were verified by DNA sequencing using T7 universal primers.

\section{Protein Purification}

The His-tagged proteins in pET-citO were overexpressed in E. coli BL21-Star(DE3) (Novagen). The cells were grown in $\mathrm{LB}$ broth at $37^{\circ} \mathrm{C}$ to an $\mathrm{OD}_{600}=0.6$. Gene expression was induced with $0.4 \mathrm{mM}$ isopropyl 1 -thio- $\beta$-D-galactopyranoside (IPTG) and the cells were further incubated at $17^{\circ} \mathrm{C}$ for $16 \mathrm{~h}$. The cells were then collected by centrifugation and stored at $-80^{\circ} \mathrm{C}$. For protein purification, the cells were resuspended in binding buffer $(500 \mathrm{mM} \mathrm{NaCl}, 5 \%$ glycerol, $50 \mathrm{mM}$ Tris $\mathrm{pH} 8.0$, and $5 \mathrm{mM}$ imidazole) with $1 \mathrm{mM}$ phenylmethylsulfonyl fluoride and disrupted using a French pressure cell press. The lysates were clarified by centrifugation ( $30 \mathrm{~min}$ at $17,000 \mathrm{~g}$ ) and applied to a metal chelate affinity column charged with $\mathrm{Ni}^{2+}$. The column was washed (in binding buffer with $15 \mathrm{mM}$ imidazole) and the proteins were eluted from the column in elution buffer (binding buffer with $250 \mathrm{mM}$ imidazole). The purified proteins were dialyzed against $10 \mathrm{mM}$ Tris $(\mathrm{pH}$ 8.0 ), $500 \mathrm{mM} \mathrm{NaCl}$, and $2.5 \%$ glycerol; aliquots were kept at $-80^{\circ} \mathrm{C}$. 


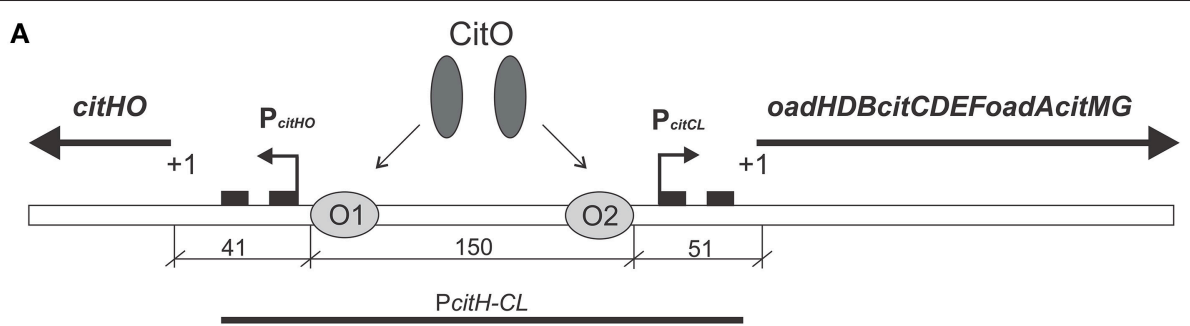

B

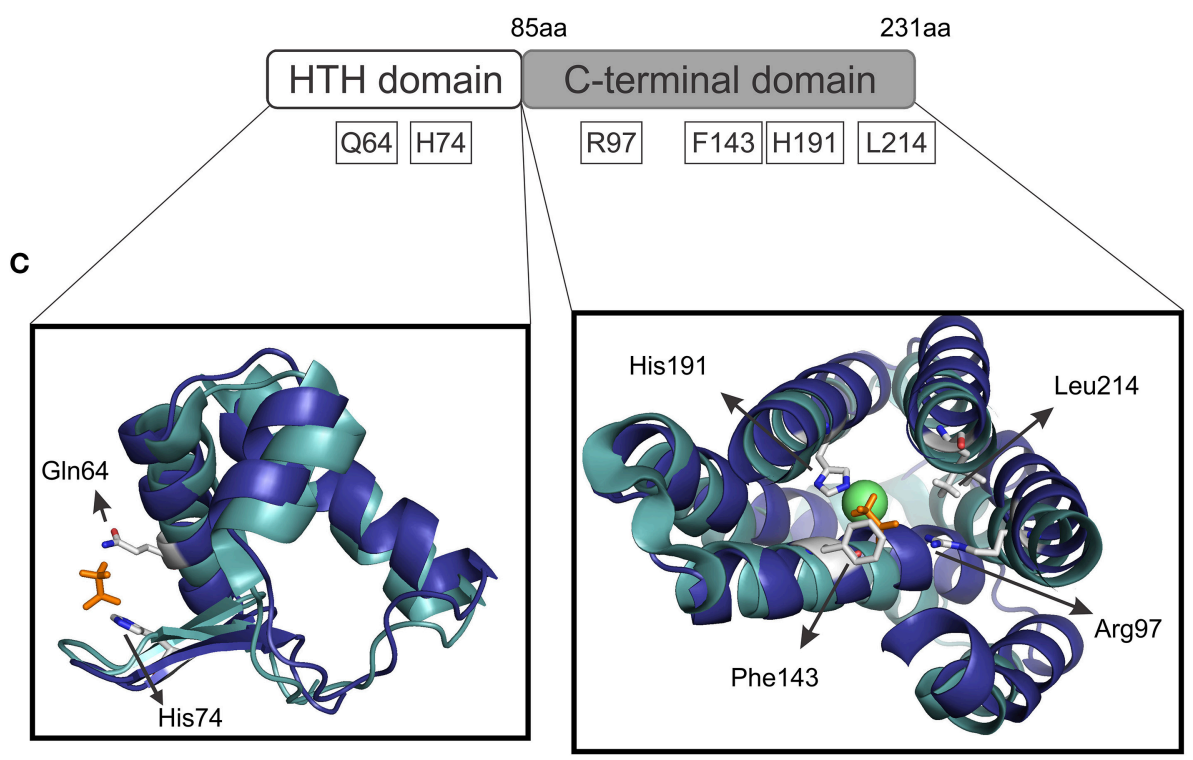

FIGURE 1 | Graphical representation of the citrate cluster and the domain organization in CitO and its predicted ligand binding pockets. (A) Schematic representation of cit operons. $P_{\text {CitHO }}$ and $P_{\text {citCL }}$ indicate promoter regions, +1 transcriptional start site, black rectangles indicate -10 and -35 boxes, $\mathrm{O}_{1}$ and $\mathrm{O}_{2}$ CitO binding sites. (B) The location of the amino acids selected in CitO for site-directed mutagenesis is indicated. (C) Close view of the residues in CitO predicted to mediate interactions with citrate and $\mathrm{Ni}^{2+}$. CitO in silico modeling (blue) was performed using the structure of TM0439 from Thermotoga maritima (PDB 3FMS, Zheng et al., 2009, cyan) as the template. In a stick representation (orange) are shown the acetate molecules, while as a green sphere is shown the $\mathrm{Ni}^{2+}$ found in $\mathrm{TM}^{2} 439$ structure. The model was visualized and analyzed using PyMol.

\section{Electrophoretic Mobility Shift Assays}

EMSA analysis of $\mathrm{CitO}$ was performed using proteins purified according to the procedures described above. A fragment of $246 \mathrm{bp}$ containing $\mathrm{CitO}$ binding sites (Blancato et al., 2008) was generated by PCR using biotin labeled (5'-end) primers (Table 2) and subsequently purified using QIAquick spin columns (Qiagen). The optimized mix for EMSA $(20 \mu \mathrm{l})$ contained $1 \mathrm{ng}$ of a $5^{\prime}$-labeled DNA fragment, $10 \mathrm{mM}$ Tris$\mathrm{HCl}$ (pH 7.5), $150 \mathrm{mM} \mathrm{KCl}, 0.5 \mathrm{mM}$ EDTA, $0.2 \mathrm{mM}$ DTT, 0.1\% Triton X-100, 12.5\% glycerol, $25 \mathrm{ng} / \mu \mathrm{l}$ Poly(dI-dC) nonspecific competitor DNA, and where indicated, purified CitO protein $(0-400 \mathrm{nM})$ or citrate $(0-5 \mathrm{mM})$. After incubation for $15 \mathrm{~min}$ at $37^{\circ} \mathrm{C}$ samples were separated on $5 \%$ acrylamide/bis-acrylamide non-denaturing gels, in $0.5 \mathrm{X}$ Tris borate-EDTA buffer, with a pH 7.5 (TBE). Electrophoresis was performed at $4^{\circ} \mathrm{C}$. The DNA was then transferred from the polyacrylamide gel to an Amersham Hybond- $\mathrm{N}^{+}$Membrane (Ge Healthcare, USA) by electroblotting at $250 \mathrm{~mA}$ for $45 \mathrm{~min}$ in a semidry transfer (Fisher Scientific, Pittsburgh, PA, USA). Transferred DNA was UV-crosslinked and biotin labeled DNA was detected using a Phototope-Star
Detection kit (NEB). Membranes were exposed to Kodak X-ray film.

\section{Size Exclusion Chromatography}

Size exclusion chromatography was performed using $200 \mu \mathrm{l}$ protein samples. Aliquots contained $28.4 \mu \mathrm{M} \mathrm{CitO}$, and where indicated, $1 \mathrm{mM}$ citrate ( $\mathrm{pH} 8.0$ ). Following $30 \mathrm{~min}$ of incubation on ice, samples were injected onto a prepacked Superdex 75 (GE Healthcare, Sweden) gel filtration column connected to a LCC501 plus (Pharmacia Biotech Inc., Piscataway, NJ) equilibrated with $50 \mathrm{mM}$ Tris (pH 7.6), $300 \mathrm{mM} \mathrm{NaCl}$, and $5 \%$ glycerol. Filtration was carried out at $4{ }^{\circ} \mathrm{C}$, using a flow rate of $0.5 \mathrm{ml} / \mathrm{min}$. The eluted proteins were monitored continuously for absorbance at $280 \mathrm{~nm}$ using a UV-M II monitor (Pharmacia Biotech Inc.). Blue dextran 2000 was used to determine the void volume of the column. A mixture of protein molecular weight standards from Bio-Rad containing bovine serum albumin $(66 \mathrm{kDa})$, albumin (45 kDa), lactalbumin $(14.2 \mathrm{kDa})$, cytochrome C $(12.7 \mathrm{kDa})$, and vitamin B12 $(1.35 \mathrm{kDa})$ were also applied to the column under similar conditions. The elution volume and molecular mass of 
TABLE 1 | Bacterial strains, and plasmids used in this study.

\begin{tabular}{|c|c|c|}
\hline Strain, or plasmid & Genotype, or description & Reference, or source \\
\hline \multicolumn{3}{|l|}{ E. coli } \\
\hline $\mathrm{DH} 5 \alpha$ & $\mathrm{F}^{-} \phi 80 \mathrm{~d} / \mathrm{lacZ} \Delta \mathrm{M} 15 \Delta(\mathrm{lacZYA}-\mathrm{arg} F) \mathrm{U} 169 \mathrm{recA} 1$ endA1 hsdR17 $\left(\mathrm{r}_{\mathrm{K}}^{-}, \mathrm{m}_{\mathrm{K}}^{+}\right)$phoA supE44 $\lambda$ - thi- 1 gyrA96 relA1 & Invitrogen \\
\hline BL21-Star (DE3) & $\mathrm{F}^{-}$ompt hsdSB(r $\left.\mathrm{r}_{\mathrm{B}}^{-} \mathrm{m}_{\mathrm{B}}^{-}\right) \mathrm{gal} d c m$ rne131 (DE3); $\mathrm{Str}^{\mathrm{r}}$ & Novagen \\
\hline \multicolumn{3}{|l|}{ E. faecalis } \\
\hline JH2-2 (TX4000) & Plasmid-free wild-type strain; Fus ${ }^{r}$ Rifr $^{r}$ & Jacob and Hobbs, 1974 \\
\hline JHB1 & JH2-2 citO::pmCitO; Em & Blancato et al., 2008 \\
\hline JHB14 & JHB1 carrying pTCV- PcitCL; Emr ${ }^{r} \mathrm{Km}^{r}$ & Blancato et al., 2008 \\
\hline JHB14-02 & JHB14 carrying pBM02; $\mathrm{Em}^{r}, \mathrm{Cm}^{r}, \mathrm{Km}^{r}$ & This work \\
\hline JHB14-wt & JHB14 carrying pCitO; $\mathrm{Em}^{r}, \mathrm{Cm}^{r}, \mathrm{Km}^{r}$ & This work \\
\hline JHB14-64 & JHB14 carrying pCitOQ64A; Emr ${ }^{r} \mathrm{Cm}^{r}, \mathrm{Km}^{r}$ & This work \\
\hline JHB14-74 & JHB14 carrying pCitOH74A; Em ${ }^{r}, \mathrm{Cm}^{r}, \mathrm{Km}^{r}$ & This work \\
\hline JHB14-97 & JHB14 carrying pCitOR97A; Emr ${ }^{r} \mathrm{Cm}^{r}, \mathrm{Km}^{r}$ & This work \\
\hline JHB14-143 & JHB14 carrying pCitOF143A; Em ${ }^{r}, \mathrm{Cm}^{r}, \mathrm{Km}^{r}$ & This work \\
\hline JHB14-191 & JHB14 carrying pCitOH191A; $\mathrm{Em}^{r}, \mathrm{Cm}^{r}, \mathrm{Km}^{r}$ & This work \\
\hline JHB14-214 & JHB14 carrying pCitOL214A; Em ${ }^{r}, \mathrm{Cm}^{r}, \mathrm{Km}^{r}$ & This work \\
\hline \multicolumn{3}{|l|}{ PLASMIDS } \\
\hline pET-28a & Expression vector for protein purification; $\mathrm{Km}^{\mathrm{r}}$ & Novagen \\
\hline pBM02 & Shuttle vector for gene expression in LAB; $\mathrm{Amp}^{r}, \mathrm{Cm}^{r}$ & Marelli and Magni, 2010 \\
\hline pTCV-lac & Promoterless vector which allows lacZ fusion construction; $\mathrm{Km}^{\mathrm{r}}$ & Poyart and Trieu-Cuot, 1997 \\
\hline pET-citO & pET28a derivative expressing $\mathrm{His}_{6}-\mathrm{CitO}$ & Blancato et al., 2008 \\
\hline pCitO & pBM02 derivative for expressing citO in E. faecalis & Blancato et al., 2008 \\
\hline pTCV-PcitCL & pTCV-lac carrying citCL promoter & Blancato et al., 2008 \\
\hline pET-citOQ64A & pET-citO with CitO Q64 $\rightarrow$ A & This work \\
\hline pET-citOH74A & pET-citO with $\mathrm{CitO} \mathrm{H} 74 \rightarrow \mathrm{A}$ & This work \\
\hline pET-citOR97A & pET-citO with CitO R97 $\rightarrow$ A & This work \\
\hline pET-citOF143A & pET-citO with CitO F143 $\rightarrow$ A & This work \\
\hline pET-citOH191A & pET-citO with CitO H191 $\rightarrow$ A & This work \\
\hline pET-citOL214A & pET-citO with CitO L214 $\rightarrow$ A & This work \\
\hline pCitOQ64A & pCitO with $\mathrm{CitO}$ Q64 $\rightarrow$ A & This work \\
\hline pCitOH74A & pCitO with $\mathrm{CitO} \mathrm{H} 74 \rightarrow \mathrm{A}$ & This work \\
\hline pCitOR97A & pCitO with $\mathrm{CitO}$ R97 $\rightarrow$ A & This work \\
\hline pCitOF143A & pCitO with $\mathrm{CitO} F 143 \rightarrow \mathrm{A}$ & This work \\
\hline pCitOH191A & pCitO with $\mathrm{CitO} \mathrm{H}_{191} \rightarrow \mathrm{A}$ & This work \\
\hline pCitOL214A & pCitO with $\mathrm{CitO}$ L214 $\rightarrow$ A & This work \\
\hline
\end{tabular}

Amp ${ }^{r}, \mathrm{Km}^{r}, \mathrm{Em}^{r}, \mathrm{Cm}^{r}, \mathrm{Fus}^{r}, \mathrm{Rif}^{r}$, and Str ${ }^{r}$ indicate resistant to ampicillin, kanamycin, erythromycin, chloramphenicol, fusidic acid, rifampicin, and streptomycin, respectively.

each protein standard was then used to generate a standard curve from which the molecular weight of eluted proteins was determined.

\section{Analysis of CitO Associated Metals}

Metal-content was determined using inductively coupled plasma atomic emission spectrometry (ICP/AES) at the IFAS Analytical Research Laboratory, University of Florida, Gainesville.

\section{Differential Scanning Fluorimetry}

The assay was carried out as described earlier (Pagliai et al., 2010). Briefly, CitO (10 $\mu \mathrm{M})$, in presence or absence of increasing concentrations of citrate or malate (the latter was used as a negative control), was placed (in duplicate) into 96-well plates (Bio-Rad, Hercules, CA) and heated from 25 to $80^{\circ} \mathrm{C}$ at the rate of $1^{\circ} \mathrm{C}$ per min. The unfolding of the protein was monitored by the increase in fluorescence of the fluorophore SYPRO Orange (Invitrogen). Fluorescence intensities were plotted against temperature for each sample well and transition curves were fitted with the Boltzmann equation using Origin 8 software (Northampton, MA). The midpoint of each transition curve was calculated and values obtained in presence of the ligand compared to those calculated for $\mathrm{CitO}$ in absence of the ligand.

\section{Isothermal Titration Calorimetry}

Measurements were performed on a VP-Microcalorimeter (MicroCal, Northampton, MA) at $25^{\circ} \mathrm{C}$. The proteins were thoroughly dialyzed against $10 \mathrm{mM}$ Tris ( $\mathrm{pH} 8.0$ ), $500 \mathrm{mM}$ $\mathrm{NaCl}$, and $2.5 \%$ glycerol. A solution of citrate (1 mM, pH 8.0) was directly prepared in dialysis buffer. Each titration involved a series of $3 \mu \mathrm{l}$ injections of the effector molecule into the protein solution. The mean enthalpies measured from injection 
TABLE 2 | Oligonucleotides used in this study.

\begin{tabular}{ll}
\hline Primer & Sequence $\left(\mathbf{5}^{\prime} \rightarrow \mathbf{3}^{\prime}\right)$ \\
\hline EMSA PROBE & \\
CitOE-F & GTGTGAGAATATACAAACTTCGCAG \\
CitOE-R & GGTATACGTTCATTATAGAAAAACCG \\
SITE DIRECTED MUTAGENESIS & \\
CitOQ64A-F & GACGCCCATTCGCTTGCTTAGCAGAATTGGTCAAAGAACAATTG \\
CitOQ64A-R & CAATTGTTCTTGACCAATCTGCTAAAGCAAAGCGAATGGGCGTC \\
CitOH74A-F & GTCAAAGAACAATTGGGGAGCTATACCTATGGTGGGTATCGTG \\
CitOH74A-R & CACGATACCCACCATAGGTATAGCTTCCACCAATTGTTCTTGAC \\
CitOR97A-F & GCTTATGAAATTATGATATTGCTAAATCTTGGACACTTAGC \\
CitOR97A-R & GCTAAAGTGTCCAAAGATTAGCAATATCATAAATTCATAAGC \\
CitOF143A-F & GTAGATGACTTACTACAGAACGCTTCAGATTTAATTCCTTATTTATAC \\
CitOF143A-R & GTATAAATAAAGGAATAAAATCTGAAGCGTTCTGTAGTAAGTCATCTAC \\
CitOH191A-F & CGTAGTATTGCCCTAGAAGAAGCTTGGTAATTTCCGCG \\
CitOH191A-R & CGCGGAAATTAACCAAGCTTCTTCTAGGGCAATACTACG \\
CitOL214A-F & CACTITAACCCATGAACATGCAAATCGTTCGCTTCAATTATITG \\
CitOL214A-R & CAAAATAAATTGAAGCGAACGATTGCATGTTCATGGGTTAAAAGTG \\
\hline
\end{tabular}

of the ligand in the buffer were subtracted from raw titration data prior to data analysis with Origin 8 software (MicroCal). Titration curves were fitted by a nonlinear least squares method to a function for the binding of a ligand to a macromolecule (Wiseman et al., 1989). From the curve thus fitted, the parameters $\Delta H$ (reaction enthalpy), $K_{A}$ (binding constant, $K_{A}=1 / K_{D}$ ), and $N$ (reaction stoichiometry) were determined. From the values of $K_{A}$ and $\Delta H$, the changes in free energy $(\Delta G)$ and entropy $(\Delta S)$ were calculated with the following equation: $\Delta G=-\mathrm{RT} \ln K_{A}=$ $\Delta H-\mathrm{T} \Delta S$; where $\mathrm{R}$ is the universal molar gas constant and $\mathrm{T}$ is the absolute temperature.

\section{Structure Modeling and Analysis}

Phyre2 (http://www.sbg.bio.ic.ac.uk/phyre2/html/page.cgi?id= index; Kelley et al., 2015) was used to model the tridimensional structure of CitO. PDB entries 3FMS and 3C7J were retrieved as the highest scoring templates. PDB 3FMS corresponds to the protein TM0439, a putative transcriptional regulator from Thermotoga maritima (Zheng et al., 2009), while PDB 3C7J corresponds to a transcriptional regulator from Pseudomonas syringae pv. tomato str. DC3000. The structural models were visualized using the PyMOL molecular graphics system v1.3 (http://www.pymol.org/, Schrödinger, LLC).

\section{$\beta$-Galactosidase Assays}

Overnight cultures of E. faecalis cells transformed with a reporter plasmid and/or a control plasmid grown in LB glucose containing containing kanamycin, erythromycin, and chloramphenicol were diluted to an $\mathrm{OD}_{600}=0.08$ and subsequently cultured in fresh LB medium supplemented with or without $17 \mathrm{mM}$ citrate. At early stationary phase $\left(\mathrm{OD}_{600}=0.8\right)$, the cells were permeabilized with $0.15 \%$ sodium dodecyl sulfate (SDS) and $1.5 \%$ chloroform in Z-buffer $\left(60 \mathrm{mM} \mathrm{Na}_{2} \mathrm{HPO}_{4}, 40 \mathrm{mM} \mathrm{NaH}_{2} \mathrm{PO}_{4}, 10 \mathrm{mM} \mathrm{KCl}\right.$, $1 \mathrm{mM} \mathrm{MgSO} 4,50 \mathrm{mM} \beta$-mercapthoethanol). $\beta$-galactosidase activity was colorimetrically determined using ONPG as a substrate at $420 \mathrm{~nm}$. The activity was quantified as described by Miller (1972), and subsequently normalized to the CitO protein concentration determined by western blot, and expressed as arbitrary units (AU). The assays were performed in triplicate. The reporter plasmid, pTCV-PcitCL (Table 1) (Blancato et al., 2008), was used to determine $\mathrm{P}_{\text {citCL }}$ promoter activity. The basal AU was determined from assays performed with the empty plasmids (pBM02 and pTCV-lac, Table 1).

\section{Western Blot Analysis}

E. faecalis strains were grown at $37^{\circ} \mathrm{C}$ for $6 \mathrm{~h}$ in $\mathrm{LB}$ medium in the presence or absence of $17 \mathrm{mM}$ citrate. Cells were harvested by centrifugation and the cell free extracts were prepared by vortexing cells with glass beads (425-600 microns, Sigma-Aldrich). Proteins were separated by sodium dodecyl sulfate-polyacrylamide gel electrophoresis (SDS-PAGE) on a $12 \%$ polyacrylamide gel, and transferred to a nitrocellulose membrane by electroblotting. Proteins were detected using primary antibody rabbit polyclonal antisera against $\mathrm{CitO}$ of E. faecalis. Antibodies were visualized by using a secondary anti-rabbit antibody coupled to alkaline phosphatase (Bio-Rad).

\section{RESULTS}

\section{Functional Analysis of the CitO Ligand Binding Pocket}

We previously established that $\mathrm{CitO}$ induced the expression of the cit operons by specifically binding citrate (Blancato et al., 2008). To determine the citrate binding site, a structural model of $E$. faecalis $\mathrm{CitO}$ was constructed using Phyre2. The structure of TM0439 from T. maritima (PDB 3FMS, Zheng et al., 2009) was retrieved as the highest scoring template (Figure 1). The obtained model had a 90\% of coverage, a QMEAN Z-score of -2.97 (Benkert et al., 2011), and 19\% identity with TM0439 
(Supplementary Figure S1). The structure of TM0439 was solved with two molecules of acetate; one localized in the N-terminus and the second in the C-terminus next to a $\mathrm{Ni}^{2+}$ atom. We performed a structural alignment between CitO and TM0439, with the associated acetate molecules used as an indication of the potential binding pocket for citrate in CitO. Although the C-terminus is associated with the binding of effector molecules, the binding site located in the HTH domain was not discarded in our studies. To determine which pocket is the biologically active site, the relevant residues surrounding the acetate molecules were selected for further analyses (Figures 1B,C). In the HTH domain, amino acids Q64 and H74 were selected. In the C-terminal domain, six residues within $3 \AA$ to the acetate molecule were identified (R97, F143, N147, H191, H213, and L214). Specifically, residues N147, H191, and $\mathrm{H} 213$ were located in the proximity of the acetate molecule and in close distance to a $\mathrm{Ni}^{2+}$ atom associated with the protein. Based on these observations, we hypothesized that a cation may facilitate the binding of the ligand to the protein or be involved in shaping the binding groove. The residues Q64, H74, R97, F143, H191, and L214 were mutated to alanine and the proteins were subsequently purified. The effect of each individual mutation was then evaluated based on their ability to bind DNA and/or citrate, and their biological relevance was validated in vivo.

The ability of CitO or its mutant variants to bind DNA was determined using a $246 \mathrm{bp}$ fragment $\left(P_{\text {citH-CL }}\right)$ containing the promoter region of the citHO operon $\left(P_{c i t H}\right)$ and the citCL operon $\left(P_{c i t C L}\right)$ harboring both the $\mathrm{O}_{1}$ and $\mathrm{O}_{2}$ binding sites (Figure 1A). It was observed that the binding of $\mathrm{CitO}$ wild type protein $(\mathrm{CitO}-\mathrm{wt})$ to this region resulted in multiple unstable complexes. The stability of the CitO-DNA complexes increased with $\mathrm{CitO}$ concentrations (up to $400 \mathrm{nM}$ ) and with the addition of citrate (up to $5 \mathrm{mM}$ ) to the binding reaction (Figure 2). Although several binding buffers were tested, a defined band for the protein-DNA complex was not obtained.

Once the binding conditions for CitO-wt were optimized, the ability of mutants in CitO to bind DNA was evaluated. The results obtained with EMSA (Figure 2) allowed the classification of mutations in four groups: group I showed no effect on DNA or citrate binding (Q64A). Group II showed both a decrease in DNA binding and less response to citrate (H74A, R97A, and H191A). Group III showed a decrease in DNA binding but was able to increase DNA binding in the presence of citrate (L214A). Group IV showed DNA binding comparable to CitO-wt in absence of citrate, but it had a dramatic increase in DNA binding when citrate was added to the reaction mix (F143A).

The mutation Q64A (located in the DNA binding domain) showed a similar DNA and ligand binding pattern compared to CitO-wt. CitO-Q64A showed some DNA binding at $200 \mathrm{nM}$ protein. In presence of citrate, the ability of this protein to bind the DNA probe used was comparable to the wild type. These results suggest that Q64 is not critically involved in DNA or citrate binding.

The mutations on H74A (located in the DNA binding domain), R97A, and H191A (located in the C-terminal domain) severely affected the DNA binding. With CitO-H74A, a faint protein:DNA complex was observed only after $200 \mathrm{nM}$ protein was used. Meanwhile, with the proteins carrying the mutations R97A or H191A, the complex was detectable at the lowest concentration of protein used $(100 \mathrm{nM})$. The addition of citrate

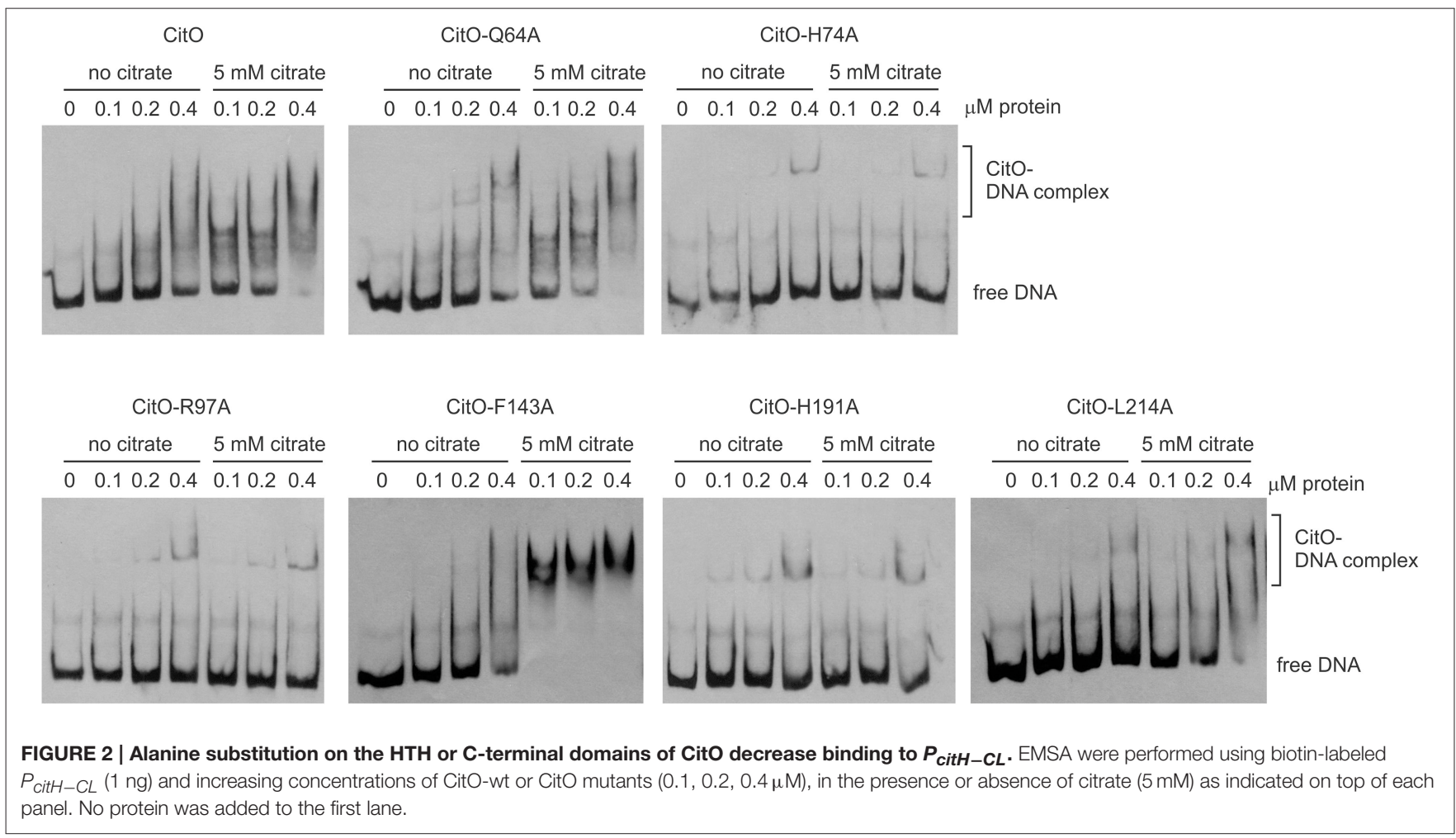


did not modify the formation of protein:DNA complexes when compared with CitO-wt (Figure 2). These results indicate that H74, R97, and H191 amino acids could be involved in the interaction with DNA, citrate, or both.

The L214A mutation (located in the C-terminal domain) showed decreased DNA binding compared to CitO-wt. The addition of citrate increased the binding of CitO-L214A to $P_{c i t H-C L}$ to a level similar to CitO-wt (Figure 2).

CitO-F143A, a mutation located in the C-terminal domain, showed a similar DNA binding pattern to CitO-wt in absence of citrate. Surprisingly, in presence of $5 \mathrm{mM}$ citrate a strong shift in the CitO-F143A was observed, suggesting higher affinity of the protein for the ligand (Figure 2).

\section{Mutations in the C-Terminal of CitO Modify its Thermal Stability in the Presence and in the Absence of Citrate}

Gel shift assays indicated that specific amino acid substitutions affected the ability of CitO to bind DNA, as well as the binding of the effector molecule citrate. To identify the residues involved only in citrate binding, differential scanning fluorimetry (DSF) followed by isothermal titration calorimetry (ITC) analyses were performed.

DSF was carried out by monitoring the increment in fluorescence of SYPRO orange due to protein unfolding. The proteins were subjected to DSF in presence and absence of ligands. CitO-wt showed two apparent melting temperatures
$(\mathrm{Tm})$ in DSF analyses (Figure 3): $\mathrm{Tm}_{1}=43^{\circ} \mathrm{C}$ and $\mathrm{Tm}_{2}=$ $58^{\circ} \mathrm{C}$. This effect may result from the sequential unfolding of the different protein domains or changes in oligomerization of the protein (Niesen et al., 2007; Gupta and Grove, 2014). The predicted molecular weight of the $\mathrm{CitO}$ monomer is $27 \mathrm{kDa}$. Size-exclusion chromatography analysis indicated that CitO has an apparent molecular weight of $48 \mathrm{kDa}$ in solution, consistent with the predicted molecular weight of the dimer (Supplementary Figure S2). The addition of citrate did not modify the oligomerization state of $\mathrm{CitO}$ in solution. Altogether, these data indicate that different transition temperatures observed for CitO-wt may be the result of the subsequent and independent unfolding of DNA and ligand-binding domains. In agreement with this observation, the addition of citrate to CitO-wt induced a shift in the $T m_{2}$ but not on $T m_{1}$, indicative of increased protein stability upon ligand binding (Figure 3). The specificity of this interaction was determined by adding other small carboxylic acids, such us malate, succinate, or isocitrate. As expected, CitO did not show a shift in the $T m_{2}$ in presence of other small molecules. Since changes in $\mathrm{Tm}_{2}$ were associated with citrate binding to $\mathrm{CitO}$, this parameter was analyzed in all the $\mathrm{CitO}$ mutants.

CitO-Q64A melting profile was similar to CitO-wt, the addition of $5 \mu \mathrm{M}$ citrate resulted in a clear shift in $\mathrm{Tm}$, while at $50 \mu \mathrm{M}$ a higher stability was observed. Interestingly, the CitOH74A mutant showed a melting profile similar to CitO-Q64A and it was comparable to the wild type. These results indicate that $\mathrm{CitO}-\mathrm{H} 74 \mathrm{~A}$ is still able to interact with citrate in solution. Since

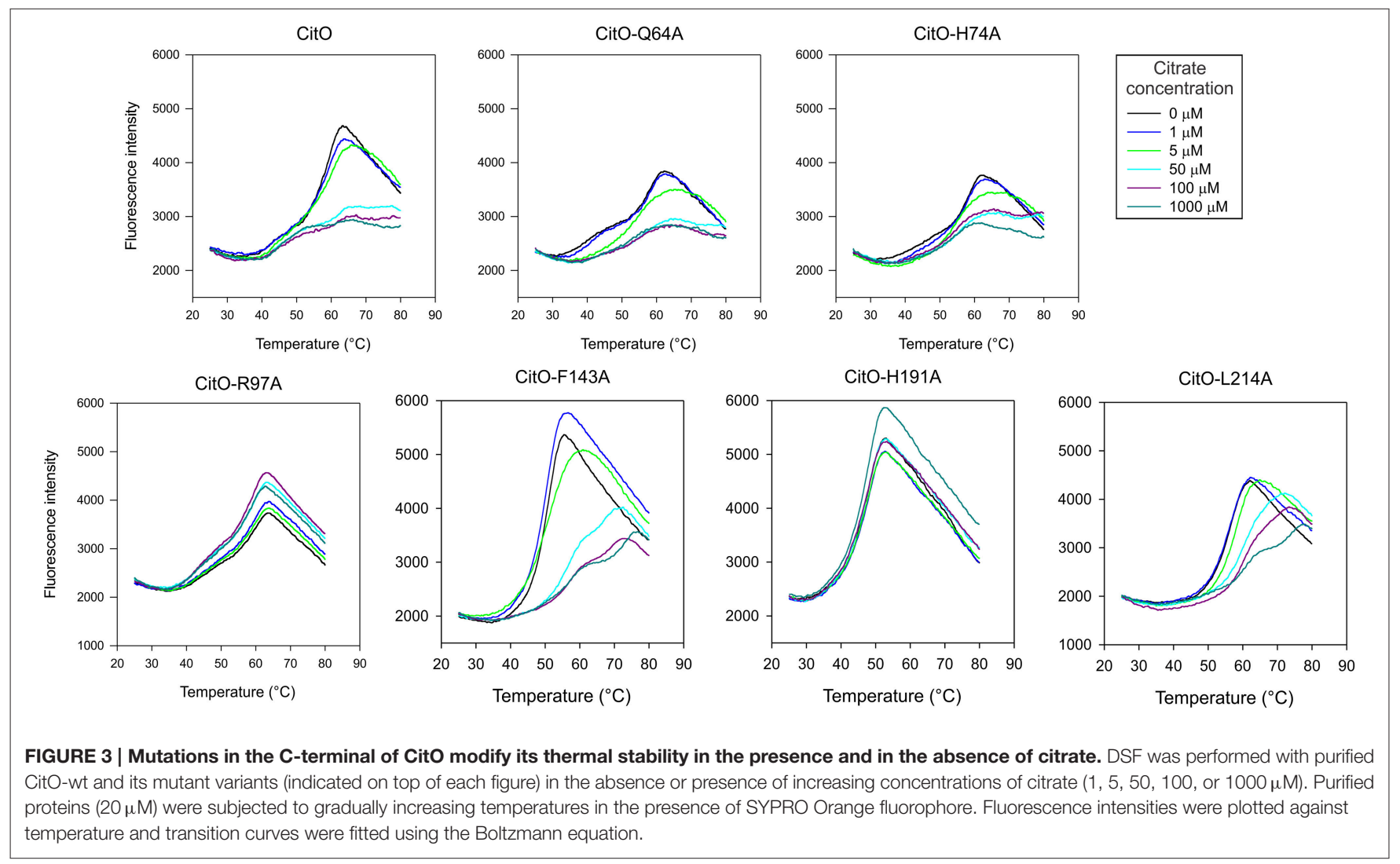


CitO-H74A binds DNA with low affinity, we hypothesized that this residue is involved in direct binding to DNA and/or in signal transduction from the $\mathrm{C}$-terminal domain to $\mathrm{N}$-terminal domain.

CitO-R97A and CitO-H191A also showed poor DNA and citrate binding on EMSA (Figure 2). DSF assays showed that in the presence or absence of citrate the protein denatured at similar temperature, even at high citrate concentrations ( $1 \mathrm{mM})$. These results suggest that $\mathrm{CitO}-\mathrm{R} 97$ and $\mathrm{CitO}-\mathrm{H} 191$ are most likely, directly involved in citrate binding.

The CitO-L214A mutant showed an increase in $\mathrm{Tm}_{2}$ $\left(\Delta T m=4^{\circ} \mathrm{C}\right.$ ) only when $50 \mu \mathrm{M}$ citrate (or higher) was present in the mixture. The CitO-F143A mutant also showed one transition curve with a $T m=50^{\circ} \mathrm{C}$. In agreement with the results obtained in EMSA, the addition of $50 \mu \mathrm{M}$ citrate induced a strong shift in the $\operatorname{Tm}\left(\operatorname{Tm}=57^{\circ} \mathrm{C}\right)$. These results suggest stronger binding of the effector molecule in the binding pocket of the regulator.

To further characterize the interactions of $\mathrm{CitO}$ and its mutated variants with the effector molecule, the thermodynamic properties of $\mathrm{CitO}$ interactions with citrate were determined using ITC. The titration of CitO with citrate followed an endothermal heat change profile, giving rise to a sigmoidal binding curve (Figure 4). The data were fitted with the Origin software using the "one set of sites model." The estimated thermodynamic parameters are summarized in Table 3. CitO-wt dissociation constant $\left(K_{D}\right)$ with citrate was in the low micromolar range $\left(K_{D}=1.2 \pm 0.2 \mu \mathrm{M}\right)$ indicating a high affinity for the ligand. Interestingly, the affinity for citrate increased in the CitOF143A mutant as evidenced by lower $K_{D}$ values (Table 3). The $\Delta H$ was positive indicating an entropically driven reaction and

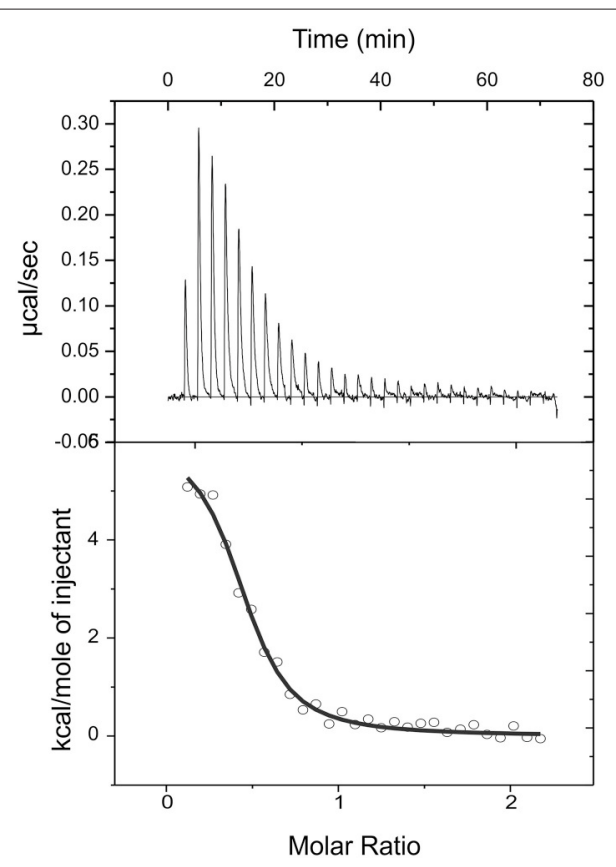

FIGURE 4 | Isothermal titration calorimetric data for the binding of citrate to CitO. Heat changes (upper panel) and integrated peak areas (lower panel) for the injection of a series of aliquots $(3 \mu \mathrm{l})$ of $1 \mathrm{mM}$ ligand in a solution of $28 \mu \mathrm{M}$ CitO. Experiments were carried out at $25^{\circ} \mathrm{C}$. the enthalpy variations were similar in the wt and all of the mutants $(\sim 6000 \mathrm{cal} / \mathrm{mol})$ with the exception of CitO-F143A, which showed a $\Delta H=16020 \mathrm{cal} / \mathrm{mol}$. In agreement with DSF assays, CitO-R97A and CitO-H191A mutants did not interact with citrate.

The stoichiometry of the reaction was $N=0.4$. Considering that $\mathrm{CitO}$ is a dimer in solution, these results suggest either the binding of one citrate molecule per dimer or that a fraction of the purified protein may contain citrate bound picked up during the heterologous expression in E. coli [citrate concentration in E. coli ranges 2-30 mM depending on growth conditions (Bennett et al., 2009)].

\section{Citrate- CitO Interactions are Mediated by a Metal Cofactor}

TM0439 has three histidines (His134, His174, and His196) in its C-terminal domain, with imidazole groups arranged in a threeblade propeller scaffold. This arrangement is usually associated with the binding of metal groups like $\mathrm{Zn}^{2+}$ or $\mathrm{Ni}^{2+}$ with high affinity. In agreement with this observation, TM0439 is able to bind these ions with $K_{D}$ values in the nanomolar range (Zheng et al., 2009). Based on the structural model, the CitO residues potentially involved in metal $\left(\mathrm{Me}^{2+}\right)$ binding were Asn147, His191, and His213. IPC-AES analysis was performed to determine if a metal atom was found in CitO-wt, or some mutant variants with different responses to citrate. It was found that CitO-wt, CitO-R97A, and CitO-F143A contained 1.02, 1.1, and 1.06 atoms of $\mathrm{Ni}^{2+}$ per molecule of protein, respectively. In contrast, in the mutant CitO-H191A, the amount of metal decreased to $0.59 \mathrm{Ni}^{2+}$ per molecule of protein. These results indicate that $\mathrm{H} 191$ is likely involved in metal interaction. Trace amounts of $\mathrm{Zn}^{2+}$ (0.05-0.07 $\mathrm{Zn}^{2+}$ per molecule of protein) were also found in all the tested proteins.

The change of H191 to Ala caused a strong effect on the ability of CitO to bind DNA and interact with citrate. These results may be explained by the reduced ability of the CitO-H191A mutant to bind $\mathrm{Me}^{2+}$. To test this hypothesis, the DNA binding ability of CitO to $P_{c i t H-C L}$, supplemented with different divalent cations, was evaluated. It was found that the addition of $\mathrm{Ca}^{2+}, \mathrm{Mn}^{2+}$, or $\mathrm{Mg}^{2+}$ did not modify the binding of CitO to $P_{\text {citH-CL}}$, while $\mathrm{Zn}^{2+}$ and $\mathrm{Ni}^{2+}$ decreased the binding (Figure 5A). In the presence of citrate, none of the $\mathrm{Me}^{2+}$ affected the binding of CitO to $P_{c i t H-C L}$ (Figure 5B).

To test the role of $\mathrm{Me}^{2+}$ in citrate binding, $\mathrm{CitO}$ was incubated in presence of $100 \mathrm{mM}$ EDTA. It was found that the depletion of $\mathrm{Me}^{2+}$ decreased the binding of CitO to $P_{c i t H-C L}$; however, just the addition of metals did not rescue the phenotype observed (Figure 5C). Moreover, it was found that the addition of citrate alone improved the formation of intermediate complexes, while the supplementation with citrate and $\mathrm{Ni}^{2+}$ or $\mathrm{Zn}^{2+}$ increased the stability of the larger CitO- $P_{c i t H-C L}$ complexes (Figure 5D). These results indicate that citrate binding to CitO is mediated by a metal cofactor, and that these interactions are required for $\mathrm{CitO}$ binding to $P_{c i t H-C L}$.

These results were confirmed by testing the mutants CitOR97A, which is irresponsive to citrate but it is still able to bind metal; and CitO-H191A, which is irresponsive to citrate and it 
TABLE 3 | Thermodynamic parameters derived from the calorimetric titration of CitO variants with citrate.

\begin{tabular}{|c|c|c|c|c|c|}
\hline Protein & $K_{D}(\mu \mathrm{M})$ & $N$ & $\Delta H(\mathrm{cal} / \mathrm{mol})$ & $\mathrm{T} \Delta \mathrm{S}$ (cal/mol/deg) & $\Delta G(\mathrm{cal} / \mathrm{mol})$ \\
\hline CitO-wt & $1.2 \pm 0.2$ & 0.44 & 6122 & 47.3 & -7983.4 \\
\hline CitO-Q64A & $0.77 \pm 0.1$ & 0.27 & 6724 & 50.5 & -8340 \\
\hline CitO-H74A & $0.82 \pm 0.04$ & 0.33 & 6500 & 50.2 & -8434.6 \\
\hline CitO-R97A & $\mathrm{ni}^{*}$ & $\mathrm{ni}^{*}$ & $\mathrm{ni}^{*}$ & $\mathrm{ni}^{\star}$ & $\mathrm{ni}^{*}$ \\
\hline CitO-F143A & $0.44 \pm 0.08$ & 0.34 & 16020 & 82.9 & -8685.7 \\
\hline CitO-H191A & $\mathrm{ni}^{*}$ & $\mathrm{ni}^{*}$ & $\mathrm{ni}^{*}$ & $\mathrm{ni}^{\star}$ & $\mathrm{ni}^{\star}$ \\
\hline CitO-L214A & $1.2 \pm 0.2$ & 0.123 & 5780 & 46.5 & -8070 \\
\hline
\end{tabular}

*no interaction.

has decreased amounts of bound metal. As expected, the addition of citrate or metals did not increase the binding of both mutant proteins to $P_{c i t H-C L}$ (data not shown). The pretreatment of CitO-R97A and CitO-H191A with EDTA showed similar results (Figures 5E,F).

\section{Mutations in the CitO Citrate Binding Pocket Reduced In vivo Expression of $P_{\text {citCL }}$}

The effect of mutations in CitO was determined in vivo by using a $P_{\text {citCL }}$ fusion to lacZ (pTCV-PcitCL plasmid, Table 1). E. faecalis JHB1 was transformed with pTCV-PcitCL (Strain JHB14). Strain JHB14 was subsequently transformed with pCitO derived plasmids (Table 1), which allowed the constitutive expression of the wild type or mutant forms of CitO. Strain JHB14-02 carrying the empty pBM02 plasmid was used as a negative control (Table 1). The densitometry analysis of $\mathrm{CitO}$ immunoreactive bands (Figure 6B) was used to normalize the reporter activity.

It was found that in the absence of citrate, strains carrying CitO-Q64A, CitO-F143A had a two-fold reduction in the $\beta$ galactosidase activity compared to CitO-wt. Strain JHB14-191, carrying CitO-H191A, showed a four-fold reduction in the base level activity, while strains JHB14-74, JHB14-97, and JHB14-214 (carrying CitO-H74A, CitO-R97A, and CitO-L214A, respectively) showed activity levels similar to the empty plasmid control. These results are in agreement with the reduced DNA binding activity found in EMSA.

When LB was supplemented with citrate, the $\beta$-galactosidase activity was induced in the strains containing $\mathrm{CitO}-w \mathrm{t}$, CitOQ64A, or CitO-F143A (Figure 6). These results are similar to the in vitro results obtained by EMSA and ITC. In contrast, strains carrying CitO-H74A, CitO-R97A, CitO-H191, or CitO-L214A showed a reduced $\beta$-galactosidase activity in presence of citrate.

The results obtained in $\mathrm{CitO}-\mathrm{H} 74 \mathrm{~A}$ mutant suggest that modifications in the HTH domain introduced in CitO-H74A resulted in a reduced DNA and citrate binding in vivo. These results contrast the DNA binding with the ITC data, where citrate binds with similar affinities to CitO-H74A and CitOwt. The apparent discrepancy can be explained by the potential involvement of $\mathrm{H74}$ in signal transduction from the DNA to the ligand binding domain in $\mathrm{CitO}$, and that its mutation affected the ability of CitO to transduce the signal between these domains.
Mutations in CitO on residues $\mathrm{R} 97$ and $\mathrm{H} 191$ showed very low $\beta$-galactosidase activity in presence of citrate. These results can be explained by the reduced DNA binding capabilities of these mutants and the reduced binding affinity of CitO-R97A and CitO-H191A for citrate observed in vitro. Based on the combined in vitro and in vivo results, we concluded that residues R97 and $\mathrm{H} 191$ in CitO mediate the binding to citrate.

In contrast to the low basal level activity observed in the CitOL214A strain in absence of citrate, the addition of citrate to the growth media resulted in a large increment in the $\beta$-galactosidase activity (64-fold). These results are similar to those obtained in EMSA (reduced DNA binding to $P_{c i t H-C L}$ ) and ITC (similar affinity for citrate as CitO-wt).

\section{DISCUSSION}

$\mathrm{CitO}$ is a transcriptional activator of the citrate metabolism in E. faecalis. It has been classified as a member of the GntR superfamily and clustered in the FCD family. The main characteristic of this subgroup of proteins was established based on the structural features of T. maritima TM0439. In this transcription factor, one nickel ion and two acetate molecules were present in the crystal structure of TM0439. Based on these findings, Zheng et al. (2009) suggested that the majority of proteins with FCD domains should be metal binding proteins. Contrary to traditional metal sensing transcription factors, such as ArsR, MerR, Fur, DtxR, or CodY, in TM0439 the metal is buried at the bottom of the ligand binding cavity. The buried location of the metal suggested an important contribution of the metal center in stabilizing the overall active pocket structure. However, the role of individual amino acids in the metal or carboxylic acid binding was not assessed. In order to gain further insight on the ligand-protein interactions within the FCD domains, CitO structure was modeled in the automated mode. The structure of T. maritima TM0439 (PDB 3FMS) and PDB 3C7J corresponding to a transcriptional regulator from $P$. syringae pv. tomato str. DC3000 were retrieved as the highest scoring templates. In TM0439, the location of two acetate molecules, one in the $\mathrm{N}$-terminus and another in the C-terminus, generated uncertainties on which was the biologically relevant pocket. Although the biological role of the acetate molecules has not been determined for TM0439, their location proved instrumental in the identification of the citrate binding pocket in CitO. 


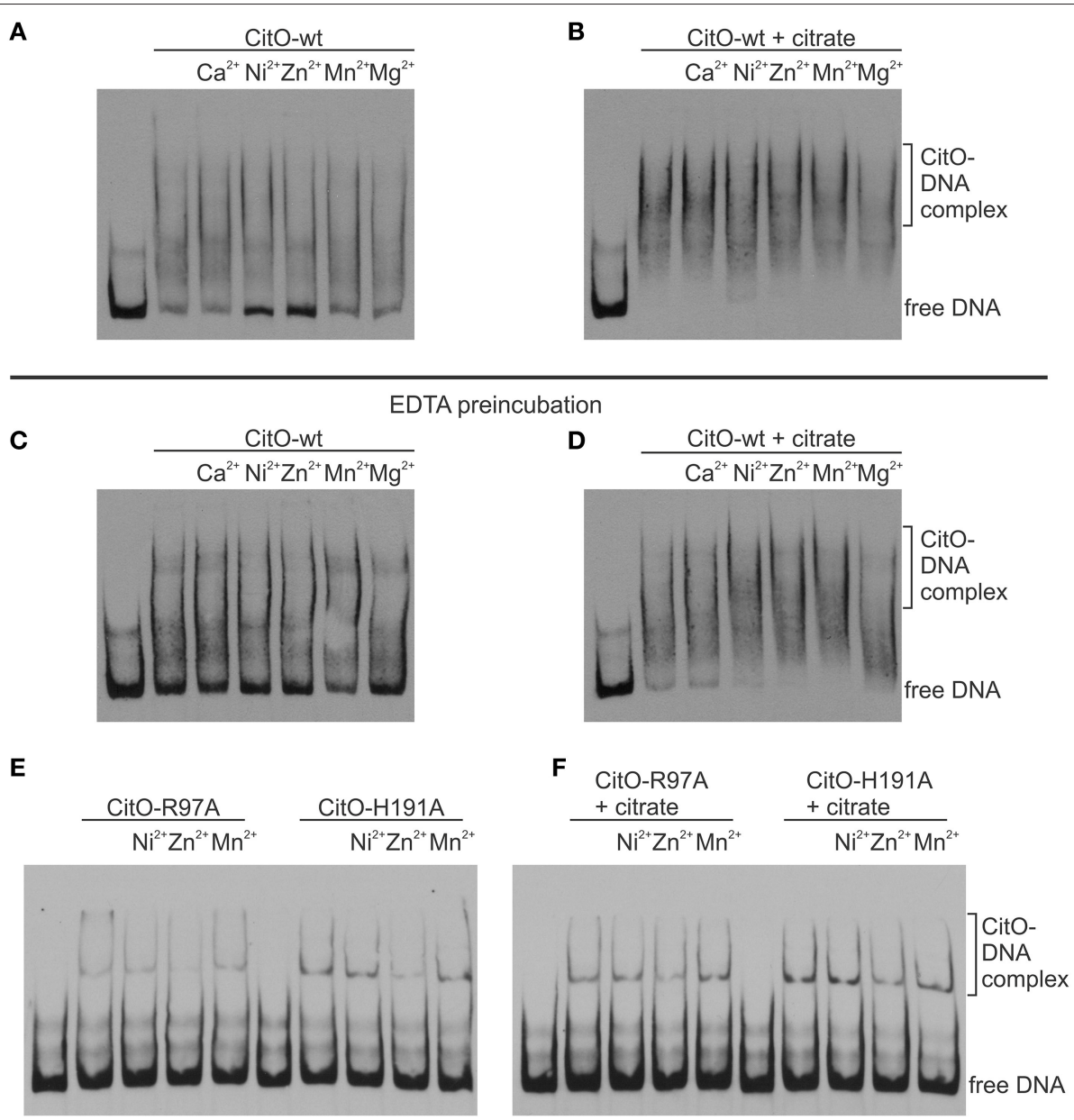

FIGURE 5 | Metal binding to CitO promotes binding to $\boldsymbol{P}_{\text {citH-CL }}$ in presence of citrate. EMSA were performed using biotin-labeled DNA (1 ng); $0.2 \mu M$ CitO-wt (A-D), CitO-R97A, or CitO-H191A (E,F); $\mathrm{Me}^{2+}(2 \mathrm{mM})$ in the absence (A,C,E) or presence of $5 \mathrm{mM}$ citrate (B,D,F). CitO used for (A) and (B), was incubated in buffer and then dialyzed, whereas the CitO-wt or mutants shown in (C-F) were incubated with EDTA for $2 \mathrm{~h}$ at $4^{\circ} \mathrm{C}$ and then dialyzed over night before conducting EMSAs.

Previous molecular data obtained with FadR from E. coli showed that acyl-CoA binds in the C-terminal domain (Raman and Dirusso, 1995; Van Aalten et al., 2000, 2001) showed that upon binding to the acyl-CoA molecule, the protein backbone undergoes dramatic conformational shifts throughout the main protein scaffold. This movement, typical of allosteric proteins, generates a rearrangement of the DNA binding domains. As a consequence of such movement, the DNA recognition helices become largely separated, preventing the interaction with the DNA molecule and consequently derepressing transcription. In order to discriminate which of the two putative citrate binding sites were active in $\mathrm{CitO}$ we performed site-directed mutagenesis at both sites. Mutations of CitO residues Q64 and H74 (located in the N-terminal domain) confirmed that CitO complies with the GntR paradigm, in which the $\mathrm{N}$-terminal domain is involved in DNA binding and not in ligand interaction. Interesting, mutagenesis of residues in the $\mathrm{C}$-terminal part of $\mathrm{CitO}$ affected both DNA and ligand binding.

In the C-terminal FCD domain, the CitO F143 residue was located in close proximity to the acetate molecule found in
TM0439. The change of F143 to alanine did not affect DNA binding in the absence of citrate. Surprisingly, a dramatic increase in DNA binding was observed upon addition of citrate. This in vitro data suggested that F143 could act as a gate keeper thereby restricting or modulating access of citrate to its binding pocket. However, CitO-F143A was less effective to induce $\mathrm{P}_{\text {citCL }}$ activity in vivo. Another interesting result was obtained with a mutant in residue L214. Although the ligand binding was not affected in the CitO-L214A mutant in vitro, the mutation appears to be critical for protein function as evidenced by the very low transcriptional activation of the $\beta$-galactosidase reporter gene in vivo. Collectively, the results indicate that although some of the residues that form the ligand binding cavity are not involved in direct contact with citrate, they may have an important role in allowing the protein to acquire an optimal conformation for DNA binding.

Conversely, CitO residues $\mathrm{R} 97$ and $\mathrm{H} 191$ were found to be essential for both DNA and ligand binding as determined by ITC, EMSA, and in in vivo tests, suggesting that those residues are in direct contact with the citrate molecule. These two residues 


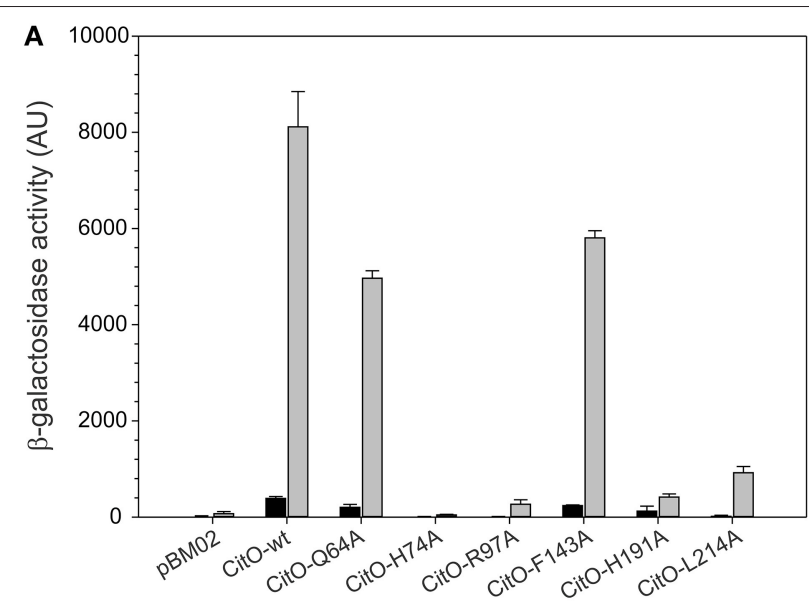

B

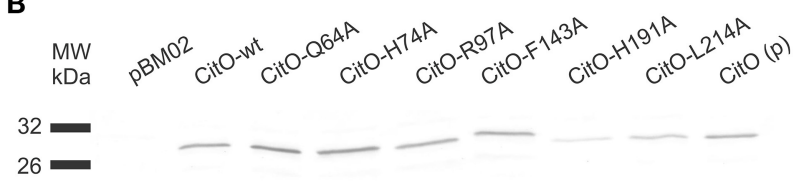

FIGURE 6 | Amino acid substitutions in CitO affect the modulatory activity of CitO on promoter activity. (A) pBM02 derived plasmids were used to express constitutively $\mathrm{CitO}$ and its variants in a citO deficient strain harboring $\mathrm{pTCV}-\mathrm{PC}$ itCL reporter plasmid. Cells were grown in the presence (gray bars) or absence (black bars) of $17 \mathrm{mM}$ citrate, and assayed for $\beta$-galactosidase activity (expressed in arbitrary units, $\mathrm{AU}$ ) after $6 \mathrm{~h}$ of growth. (B) The quantification of the protein levels by Western blot, using polyclonal antibodies against CitO, was performed by densitometry in order to calculate specific $\beta$-galactosidase activity. $\mathrm{CitO}(p) 0.1 \mu \mathrm{g}$ of purified $\mathrm{CitO}$ used as a positive control.

may also be involved in further signal transduction to the $\mathrm{N}$ terminus, allowing the correct positioning of the HTH domain on the DNA. In the E. coli biofilm repressor McbR (PDB: 4PF9), although the ligand was not defined in the structure, the residues R89 (R97 in CitO), D135 (F143 in CitO), R139 (D147 in CitO), and D211 (Supplementary Figure S1) were indicated as involved in ligand binding (Lord et al., 2014). The structural model constructed for CitO indicated that H191 is part of an Asn147His191-His213 triad involved in the coordination of a divalent cation. Accordingly, stoichiometric amounts of $\mathrm{Ni}^{2+}$ were found in CitO-wt samples, whereas the CitO-H191A mutant showed a strong reduction in $\mathrm{Ni}^{2+}$ concentrations. The decreased amount of metals in CitO-H191A correlated with a reduction on DNA and ligand binding affinities (Figures 2, 3, Table 3). These results suggest that the metal is important for protein function and that the remaining residues of the pocket (Asn147 and His213), perhaps with the aid of second sphere of coordination, could still bind $\mathrm{Ni}^{2+}$ but in a less efficient configuration. Furthermore, when the metal was removed from the CitO-wt, the protein was unable to sense the presence of the citrate (Figure 5D), indicating that both citrate and the metal are required for proper protein function.

The presence of metals in the GntR superfamily of transcriptional factors was initially reported in the repressor LldR from Corynebacterium glutamicum (PDB 2DI3) involved in Llactate and fructose/glucose utilization. $\mathrm{A} \mathrm{Zn}^{2+}$ ion was located in the structure at the core of the helical bundle with three coordinating histidine residues (His148, His196, and His218); however, the biological role of the cation in this protein was not determined (Gao et al., 2008). The metal binding site is conserved across other proteins containing the FCD domain, such as TM0349 (Zheng et al., 2009) and PS5454 from P. syringae (PDB: 3C7J; Supplementary Figure S1). These residues are also highly conserved in other sequence homologs of $\mathrm{CitO}$ found in Streptococcus mutants, Streptococcus pyogenes, Lactobacillus casei, Lactobacillus sakei, and E. faecium that are associated with the citrate fermentation pathways.

The binding of citrate in complex with a metal seems widespread in other families of transcription factors. Recently a citrate- $\mathrm{Mg}^{2+}$ binding pocket was reported for AcnR, a member of TetR family of transcriptional regulators. AcnR controls the expression of aconitase in C. glutamicum (Garcia-Nafria et al., 2013). Contrary to other TetR ligands, the citrate- $\mathrm{Mg}^{2+}$ complex was found in a second binding site distant from the DNA-binding domain, with a $K_{D}$ of $6 \mathrm{mM}$. The ligand was located with its apolar carbon atoms pointing to the hydrophobic interior and the polar atoms facing the outer side of the pocket. In AcnR, the magnesium ion is coordinated by three oxygens in the citrate, two water molecules, and the carboxyl oxygens of a glutamic acid residue (Garcia-Nafria et al., 2013).

In conclusion, previous structure-based evidence suggested that members of FCD family may act as metal-sensors or that the metal present in these domains would play a rather structural role while being required for interaction with other effector molecules. Based on the evidence presented here, we proposed that citrate interacts with the buried $\mathrm{Ni}^{2+}$ or $\mathrm{Zn}^{2+}$ molecule in the C-terminal domain, triggering conformational changes in $\mathrm{CitO}$ that reorient the $\mathrm{N}$-terminal DNA binding domain, increasing the recognition of its specific DNA target.

\section{AUTHOR CONTRIBUTIONS}

$\mathrm{VB}, \mathrm{CM}$, and GL conceived and designed the experiments. VB and FP performed the experiments. VB, CM, CG, and GL analyzed the data and wrote the paper.

\section{ACKNOWLEDGMENTS}

This work was supported by funds from the Institute of Food and Agricultural Sciences, University of Florida and funds from CONICET, Argentina (PIP 2012/14). VB was funded by a Fulbright-CONICET Visitor Scholar fellowship. We thank Christopher L. Gardner for technical support and Kaylie Padgett for the critical reading of the manuscript.

\section{SUPPLEMENTARY MATERIAL}

The Supplementary Material for this article can be found online at: http://journal.frontiersin.org/article/10.3389/fmicb. 2016.00101 


\section{REFERENCES}

Bateman, A., Birney, E., Cerruti, L., Durbin, R., Etwiller, L., Eddy, S. R., et al. (2002). The Pfam protein families database. Nucleic Acids Res. 30, 276-280. doi: 10.1093/nar/30.1.276

Benkert, P., Biasini, M., and Schwede, T. (2011). Toward the estimation of the absolute quality of individual protein structure models. Bioinformatics 27, 343-350. doi: 10.1093/bioinformatics/btq662

Bennett, B. D., Kimball, E. H., Gao, M., Osterhout, R., Van Dien, S. J., and Rabinowitz, J. D. (2009). Absolute metabolite concentrations and implied enzyme active site occupancy in Escherichia coli. Nat. Chem. Biol. 5, 593-599. doi: $10.1038 /$ nchembio. 186

Blancato, V. S., Magni, C., and Lolkema, J. S. (2006). Functional characterization and $\mathrm{Me}$ ion specificity of a Ca-citrate transporter from Enterococcus faecalis. FEBS J. 273, 5121-5130. doi: 10.1111/j.1742-4658.2006.05509.x

Blancato, V. S., Repizo, G. D., Suárez, C. A., and Magni, C. (2008). Transcriptional regulation of the citrate gene cluster of Enterococcus faecalis Involves the GntR family transcriptional activator CitO. J. Bacteriol. 190, 7419-7430. doi: 10.1128/JB.01704-07

Casali, N., White, A. M., and Riley, L. W. (2006). Regulation of the Mycobacterium tuberculosis mce1 operon. J. Bacteriol. 188, 441-449. doi: 10.1128/JB.188.2.441449.2006

Espariz, M., Repizo, G., Blancato, V., Mortera, P., Alarcón, S., and Magni, C. (2011). Identification of malic and soluble oxaloacetate decarboxylase enzymes in Enterococcus faecalis. FEBS J. 278, 2140-2151. doi: 10.1111/j.17424658.2011.08131.x

Franco, I. S., Mota, L. J., Soares, C. M., and De Sá-Nogueira, I. (2006). Functional domains of the Bacillus subtilis transcription factor AraR and identification of amino acids important for nucleoprotein complex assembly and effector binding. J. Bacteriol. 188, 3024-3036. doi: 10.1128/JB.188.8.30243036.2006

Gao, Y. G., Suzuki, H., Itou, H., Zhou, Y., Tanaka, Y., Wachi, M., et al. (2008). Structural and functional characterization of the LldR from Corynebacterium glutamicum: a transcriptional repressor involved in L-lactate and sugar utilization. Nucleic Acids Res. 36, 7110-7123. doi: 10.1093/nar/gkn827

Garcia-Nafria, J., Baumgart, M., Turkenburg, J. P., Wilkinson, A. J., Bott, M., and Wilson, K. S. (2013). Crystal and solution studies reveal that the transcriptional regulator AcnR of Corynebacterium glutamicum is regulated by citrate-Mg2+ binding to a non-canonical pocket. J. Biol. Chem. 288, 15800-15812. doi: 10.1074/jbc.M113.462440

Gupta, A., and Grove, A. (2014). Ligand-binding pocket bridges DNA-binding and dimerization domains of the urate-responsive MarR homologue MftR from Burkholderia thailandensis. Biochemistry 53, 4368-4380. doi: 10.1021/bi5 $00219 \mathrm{t}$

Haydon, D. J., and Guest, J. R. (1991). A new family of bacterial regulatory proteins. FEMS Microbiol. Lett. 63, 291-295. doi: 10.1111/j.1574-6968.1991.tb04544.x

Hoskisson, P. A., Rigali, S., Fowler, K., Findlay, K. C., and Buttner, M. J. (2006). DevA, a GntR-like transcriptional regulator required for development in Streptomyces coelicolor. J. Bacteriol. 188, 5014-5023. doi: 10.1128/JB.00307-06

Jacob, A. E., and Hobbs, S. J. (1974). Conjugal transfer of plasmid-borne multiple antibiotic resistance in Streptococcus faecalis var. zymogenes. J. Bacteriol. 117, 360-372.

Jaques, S., and Mccarter, L. L. (2006). Three new regulators of swarming in Vibrio parahaemolyticus. J. Bacteriol. 188, 2625-2635. doi: 10.1128/JB.188.7.26252635.2006

Kelley, L. A., Mezulis, S., Yates, C. M., Wass, M. N., and Sternberg, M. J. E. (2015). The Phyre2 web portal for protein modeling, prediction and analysis. Nat. Protocols 10, 845-858. doi: 10.1038/nprot.2015.053

Lee, M. H., Scherer, M., Rigali, S., and Golden, J. W. (2003). PlmA, a new member of the GntR family, has plasmid maintenance functions in Anabaena sp. Strain PCC 7120. J. Bacteriol. 185, 4315-4325. doi: 10.1128/JB.185.15.4315-432 5.2003

Lord, D. M., Uzgoren Baran, A., Soo, V. W., Wood, T. K., Peti, W., and Page, R. (2014). McbR/YncC: implications for the mechanism of ligand and DNA binding by a bacterial GntR transcriptional regulator involved in biofilm formation. Biochemistry 53, 7223-7231. doi: 10.1021/bi500871a
Marelli, B., and Magni, C. (2010). A simple expression system for Lactococcus lactis and Enterococcus faecalis. World J. Microbiol. Biotechnol. 26, 999-1007. doi: 10.1007/s11274-009-0262-5

Miller, J. H. (1972). Experiments in Molecular Genetics. New York, NY: Cold Spring Harbor Laboratory.

Niesen, F. H., Berglund, H., and Vedadi, M. (2007). The use of differential scanning fluorimetry to detect ligand interactions that promote protein stability. Nat. Protoc. 2, 2212-2221. doi: 10.1038/nprot.2007.321

Ostash, B., Rebets, Y., Myronovskyy, M., Tsypik, O., Ostash, I., Kulachkovskyy, O., et al. (2011). Identification and characterization of the Streptomyces globisporus 1912 regulatory gene $\ln d Y R$ that affects sporulation and antibiotic production. Microbiology 157, 1240-1249. doi: 10.1099/mic.0.045088-0

Pagliai, F. A., Gardner, C. L., Pande, S. G., and Lorca, G. L. (2010). LVIS553 transcriptional regulator specifically recognizes novobiocin as an effector molecule. J. Biol. Chem. 285, 16921-16930. doi: 10.1074/jbc.M110.111138

Poyart, C., and Trieu-Cuot, P. (1997). A broad-host-range mobilizable shuttle vector for the construction of transcriptional fusions to betagalactosidase in gram-positive bacteria. FEMS Microbiol. Lett. 156, 193-198. doi: 10.1016/S0378-1097(97)00423-0

Raman, N., and Dirusso, C. C. (1995). Analysis of acyl coenzyme A binding to the transcription factor FadR and identification of amino acid residues in the carboxyl terminus required for ligand binding. J. Biol. Chem. 270, 1092-1097. doi: 10.1074/jbc.270.3.1092

Repizo, G. D., Blancato, V. S., Mortera, P., Lolkema, J. S., and Magni, C. (2013). Biochemical and genetic characterization of the Enterococcus faecalis oxaloacetate decarboxylase complex. Appl. Environ. Microbiol. 79, 2882-2890. doi: 10.1128/AEM.03980-12

Reuther, J., Wohlleben, W., and Muth, G. (2006). Modular architecture of the conjugative plasmid pSVH1 from Streptomyces venezuelae. Plasmid 55, 201-209. doi: 10.1016/j.plasmid.2005.11.007

Rigali, S., Derouaux, A., Giannotta, F., and Dusart, J. (2002). Subdivision of the helix-turn-helix GntR family of bacterial regulators in the FadR, HutC, MocR, and YtrA subfamilies. J. Biol. Chem. 277, 12507-12515. doi: 10.1074/jbc.M110968200

Sambrook, J., and Russell, D. W. (2001). Molecular Cloning: A Laboratory Manual. New York, NY: Cold Spring Harbor Laboratory Press.

Truong-Bolduc, Q. C., and Hooper, D. C. (2007). The transcriptional regulators NorG and MgrA modulate resistance to both quinolones and beta-lactams in Staphylococcus aureus. J. Bacteriol. 189, 2996-3005. doi: 10.1128/JB.01819-06

Van Aalten, D. M., Dirusso, C. C., and Knudsen, J. (2001). The structural basis of acyl coenzyme A-dependent regulation of the transcription factor FadR. EMBO J. 20, 2041-2050. doi: 10.1093/emboj/20.8.2041

Van Aalten, D. M., Dirusso, C. C., Knudsen, J., and Wierenga, R. K. (2000). Crystal structure of FadR, a fatty acid-responsive transcription factor with a novel acyl coenzyme A-binding fold. EMBO J. 19, 5167-5177. doi: 10.1093/emboj/19.19.5167

Wiseman, T., Williston, S., Brandts, J. F., and Lin, L. N. (1989). Rapid measurement of binding constants and heats of binding using a new titration calorimeter. Anal. Biochem. 179, 131-137. doi: 10.1016/0003-2697(89)90213-3

Zheng, M., Cooper, D. R., Grossoehme, N. E., Yu, M., Hung, L. W., Cieslik, M., et al. (2009). Structure of Thermotoga maritima TM0439: implications for the mechanism of bacterial GntR transcription regulators with $\mathrm{Zn2+}$ binding FCD domains. Acta Crystallogr. D Biol. Crystallogr. 65, 356-365. doi: $10.1107 /$ S0907444909004727

Conflict of Interest Statement: The authors declare that the research was conducted in the absence of any commercial or financial relationships that could be construed as a potential conflict of interest.

Copyright (c) 2016 Blancato, Pagliai, Magni, Gonzalez and Lorca. This is an openaccess article distributed under the terms of the Creative Commons Attribution License (CC BY). The use, distribution or reproduction in other forums is permitted, provided the original author(s) or licensor are credited and that the original publication in this journal is cited, in accordance with accepted academic practice. No use, distribution or reproduction is permitted which does not comply with these terms. 